\title{
INCLUSIVE EDUCATION AND PERCEPTION OF IN-SERVICE TEACHERS
}

\author{
Ramakrishnan B \\ Research scholar, Dept. of Economics, Central University of Tamil Nadu, Tamil Nadu, India. \\ *Corresponding Author email: Ramakrishnan507@gmail.com \\ Article History \\ Submission: May 05, 2020 \\ Revised: June 10, 2020 \\ Accepted: June 28, 2020

\begin{abstract}
Since the Universal Declaration of Human Rights, the United Nations have brought various policies and conventions to support minorities across the world, including differently-abled persons. However, we are not where we are today without the contributions of numerous countries, developmental organizations and nongovernment institutions. For instance, we've the UN proposed Sustainable Development Goals (SDGs) and Millennium Development Goals (MDGs) that promote quality and equality in education for all, with zero rejection and discrimination, including those against children with disability (CWD). This paper systematically maps the existing literature on the perception of in-service teachers towards including CWD in a regular classroom with the challenges faced by teachers toward facilitating a uniform approach to education for all amid shortage of relevant skills and resources. Future implications and recommendations are also discussed in the paper.
\end{abstract}

Keywords: Inclusion, Teacher attitude, self-efficacy, Geographical location, CWD, Right to Education

Abbreviations: NIL

\section{INTRODUCTION}

Right to education is a fundamental right of every human. Every child must have a chance at education However, this becomes a challenge especially in the case of children with disability (CWD). People with disability in general are perceived differently by individuals, and this perception can be influenced by their culture, caste, creed, age and lifestyle (Singal, 2011). But a common trait found in most of the countries was that, education was not provided to children who were disabled physically or mentally. Only after $15^{\text {th }}$ century, the idea of educating children with certain disabilities started (Kisanji, 1999) across the world. Scientists and educationists started developing new methods for educating children with disability and as a result, methods like Braille (for visually impaired) and sign language (for deaf and dumb) were invented for providing education for children with sensory impairment. In 1901, Decroly found a new pedagogy for teaching children with learning disabilities, including those with mild intellectual and behavioural disabilities.

Slowly special schools started emerging as a supplement for general schools (Andriichuk, 2017). Children who were unable to attend the general schools or who required special care were admitted in these schools that had tailor-made programs for CWD. This led to the development of two education systems viz., regular and special education (Kisanji, 1999). This prompted the educational institutions to introduce educational courses specific to train the educators to teach CWD in special schools. 
During the second half of $20^{\text {th }}$ century, people started questioning institutionalization of CWDs, which paved way for integrating and including special children with their normal peers. Thus, integration and inclusion became buzz words with a little knowledge of what they were and way to achieve them (Singal, 2011). In inclusion, the school environment should adopt to the children while in integration, children have to adopt to school environment. Most of the time stakeholders and policy makers get confused between these two terms which has also reflected in policies created for inclusive education (Lindsay, 2007; Singal, 2005; Vislie, 2003). The concept of inclusion started in the West (Deng and Poon-McBrayer, 2004; Kim, 2012) and spread worldwide. Many countries started re-forming and re-defining their legislations and policies. For instance, Canada, India, Philippines, and Australia created legislation for inclusive education, whereas countries like Singapore, Hong Kong, and Brunei re-defined their educational policies.

For more than three decades, educationists and stakeholders are talking about inclusion and inclusive education. Still effective implementation of IE is lacking in many countries. For instance, in 2003, almost a decade after Salamanca statement, only 11 percent of urban and less than 1 percent of rural CWD attended special schools, and only 18 percent of urban and 7 percent of rural CWD crossed secondary education in India (Kalyanpur, 2008). The reasons behind ineffective inclusive policies are lack of material resources, infrastructure, deficit funding and professional development. In addition to this, the socio-cultural ethnicity, perception about the disabled, negative attitude among population etc., made it difficult for the countries in implementing IE successfully. Still people from countries like India, Africa, Brunei etc., view disability as a punishment for misdeeds.

Among the factors responsible for successful inclusive education, the role of educators is inevitable. Policies can only pave way for implementing inclusive education. It's the responsibility of the educators to efficiently teach in an inclusive set up. It can be possible only if the educators are well equipped with professional skills, positive attitude, willingness, high self-efficacy and confidence to teach CWD in an inclusive classroom. Many a times, teachers are not provided with adequate support to teach CWD in regular schools contributing to a general reluctance in adhering to the IE policy.

Are teachers ready to include children with disability in regular classroom? If not, which factor hinders the teacher from including CWD? Is it only the attitude and efficacy of teachers that determine the success of inclusive education? To answer all these questions, this paper tries to systematically map the available literature on inservice teacher's perception and attitude towards inclusive education.

\section{METHODOLOGY:}

- Search strategy: For this systematic search, a search strategy was developed to identify relevant literature. This search strategy was confined to 'Science Direct' database and the terms used for the search included 'inclusive education', 'disability', and 'teachers' attitude'. The search included articles till 2020 and is limited to those published in English. 
- Selection Criteria: The selection criteria were based on the PRISMA statement (Moher et. al., 2009). The search focused mainly on mapping the existing literature regarding 'Inclusive Education' in the field of Social Sciences which was further narrowed down to Education and Psychology. All articles published before 2011 were excluded and only those articles published between 2011 and 2020 were included. The search focused on 'In-service teacher's attitude towards inclusive education' across countries. A total of 775 articles were extracted at this stage.

- Quality Assessment: The study was based only on original research articles. For maintaining the quality of review all duplications were checked thoroughly and removed. Abstracts of the articles were checked deeply for the analysis and those studies out of scope were also excluded. After applying the above-mentioned filters, 653 articles were excluded and 122 relevant articles were included in the study. A second round of quality assessment was made to include the articles with high relevance. In the second stage of quality assessment, 92 articles were excluded from the study.

- Data extraction: A total of 30 articles were selected (see Chart 1) and the characteristics of those extracted fulfilled the criteria of original research paper and case study and not a published reports, review paper and conference paper; English language and from the field of Social Sciences; published between 2011 and 2020.

\section{RESULTS AND INTERPRETATION:}

When the selected articles are classified based on year of publication, we could see that more were published in 2015 and 2017 (6 articles each) and the least number was published in 2016, 2018 and 2020(1 article each).

\section{Total}

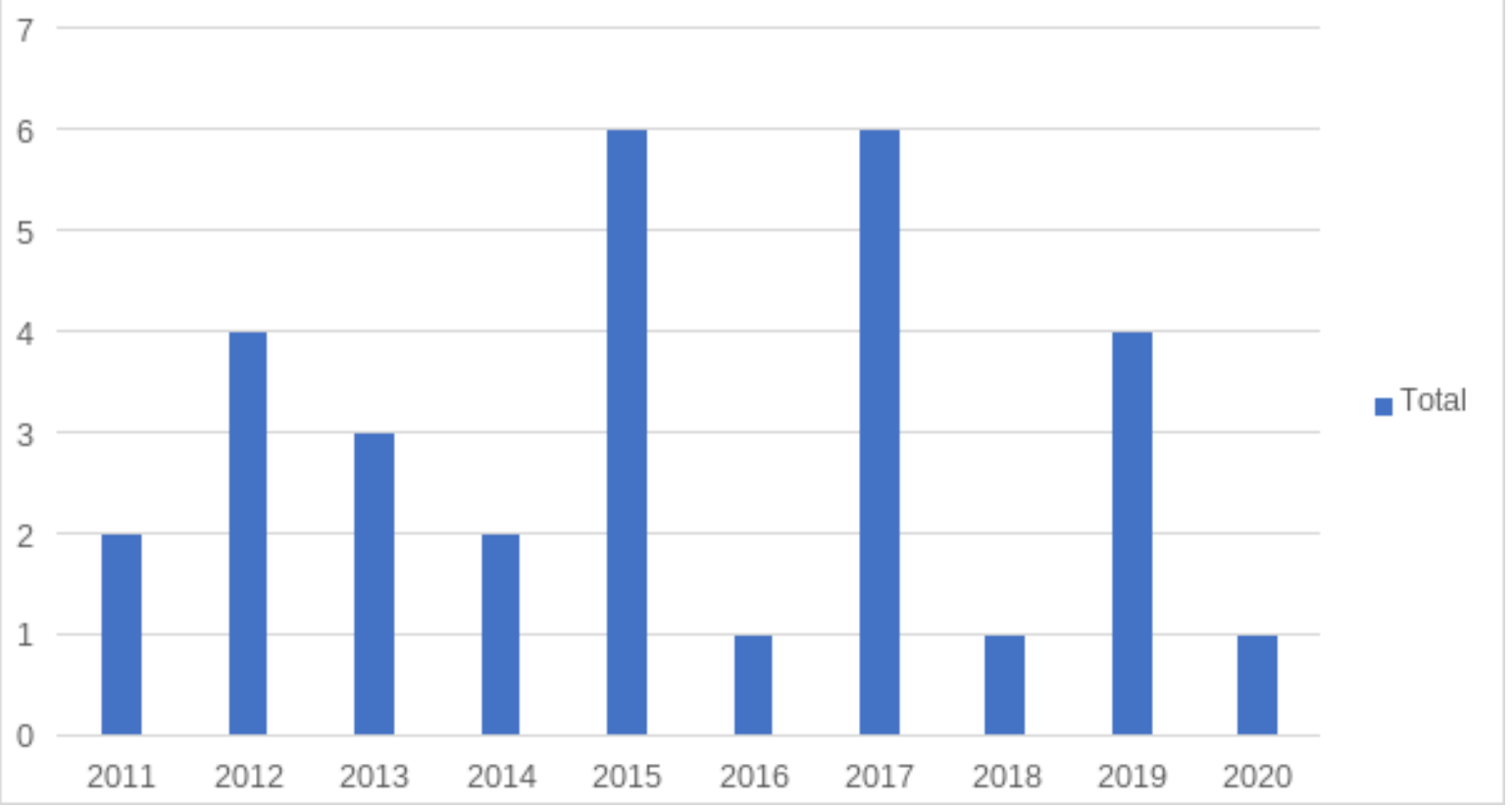


Chart 1: Distribution of selected articles based on the year of publication (2011-2020)

All the 30 articles chosen for the study were published in six different journals. Fourteen articles were published in 'Teaching and Teacher Education' and nine articles in 'Procedia - Social and Behavioural Sciences' which were the highest. The least number of articles chosen for the study were published in 'Research in Developmental Disabilities' and 'Kasetsart Journal of Social Sciences' (1 each in both journals).

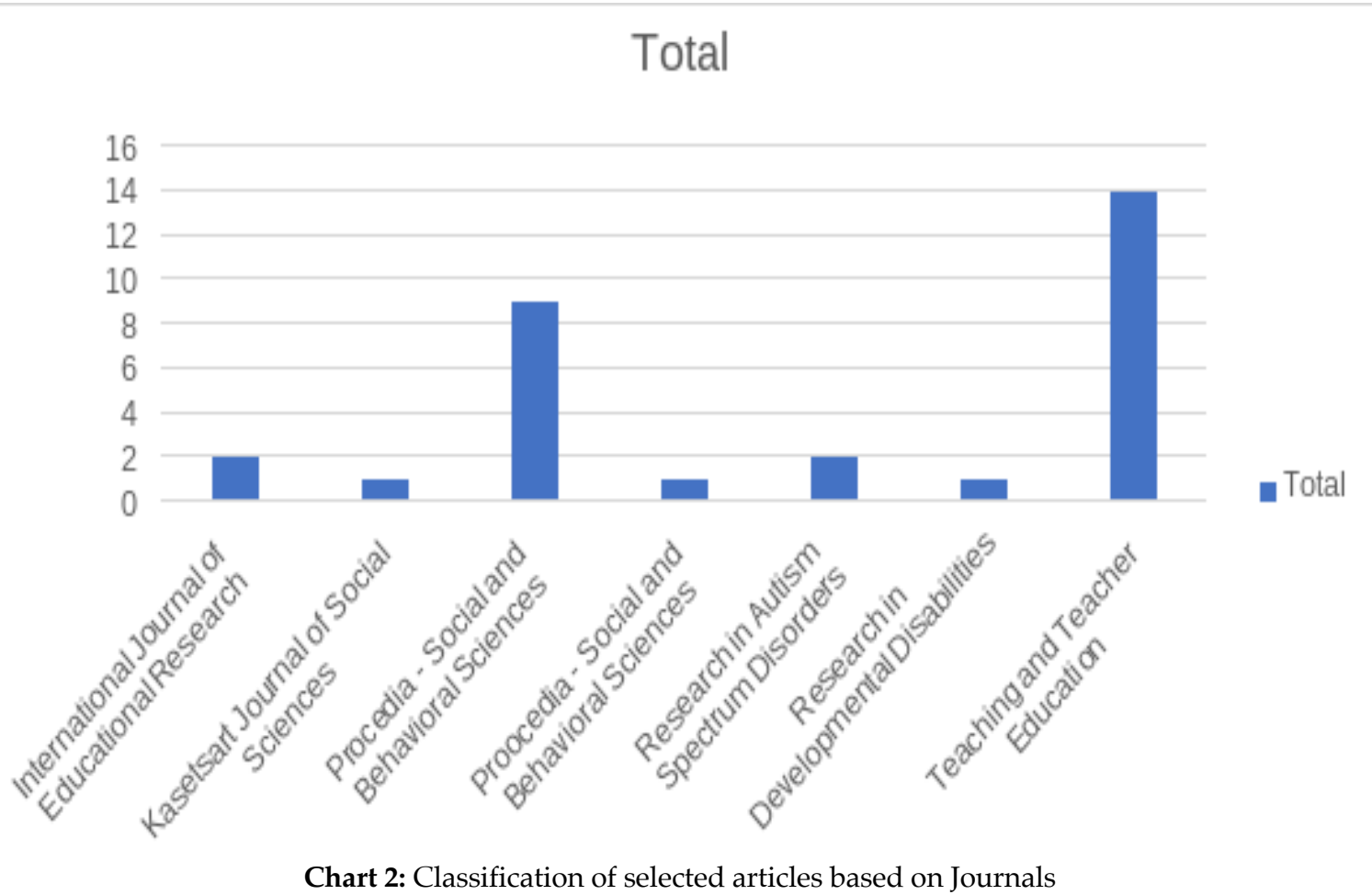

To analyse the perception of teachers about the inclusion of children with disability in regular schools, the articles taken for the study have been segregated into Eastern and Western countries. This will allow us to understand the perception of teachers in two angles. One, understanding the difference in perception of teachers from the development-based Western background and teachers from a culture-based Eastern background; and two, the difference in perception between the teachers from countries where IE was born (West) and in the countries that adopted IE (East).

\section{PERCEPTIONS IN THE WEST:}

Most of the Western countries are well developed with all sorts of resources to include CWD in regular classroom. Still negative perceptions are seen among teachers in some countries. This might be because of scarce resources, inadequate funds, lack of support from special teachers, inappropriate knowledge about inclusive education and overcrowded classrooms (Vendova and Fialov, 2015). Due to administrative workload and shortage of time, the teachers are not ready to understand the benefits of inclusive education (Dias, 2015). These negative constraints has led to poor practical outcome of inclusive policies in many Western countries (Young et. al., 2017). Irrespective of their designation (either primary, secondary or university), teachers lacked clarity on the 
concept of inclusion (Vendova and Fialov, 2017; Unianu, 2012), awareness about inclusive norms and national laws (Costea-Bafrluaiu and Rusu, 2015).

The research so far has also given some prompts on the varied attitude the educators hold. Primary teachers show more positive attitude than secondary teachers (Todorovic et. al., 2011) because secondary teachers have more academic work and heavy syllabus to complete within stipulated time. So, they do not generally wish to include children showing negative work attitude (Vermeulen et. al., 2012) and children with moderate or severe disability. This negative attitude could be changed if the in-service teachers are provided with practical training in inclusive classroom (MacFarlane and Woolfson, 2013). Even courses on inclusive education can provide the teachers with a proper understanding of the problem, increase the self-efficacy and reduce the concerns regarding inclusion. (Kormos and Nijakowska, 2017)

Table 1: Distribution of articles based on geographical location

\begin{tabular}{lll}
\hline Geographical Division & Continents & Article count \\
\hline \multirow{2}{*}{ East } & Africa & 1 \\
& Asia & 14 \\
West & Europe & 12 \\
Grand Total & North America & 3 \\
\hline
\end{tabular}

\section{PERCEPTIONS IN THE EAST:}

The Eastern countries are known for their rich culture. Culture plays a major role in determining the characteristics of an individual, and society as a whole. On one side, countries are moving towards development and technological improvisation, but on the other side, cultural beliefs have marginalized certain group of people. People with disabilities are one among the minorities who lack care and support. The sociocultural ideologies determine the attitude of teachers (Tiwari et. al., 2015) and their intention to teach CWD (Sharma and Jacobs, 2016). The cultural beliefs of teachers increased the positive attitude towards CWD but the prevailing systematic barriers like inadequate training for in-service teachers, improper infrastructure, inflexible syllabi etc., has increased the negative concerns about inclusion (Yada and Savolainen, 2017) and made inclusion a success only in paper and not in practice (Tiwari et. al., 2015).

The inadequate training of regular teachers to teach CWD increases the possibility of reduced self-confidence and efficacy than special teachers who are properly trained to handle CWD (Hettiarachchi and Das, 2014). The teachers also do not find an important role to play in providing education to CWD (Gavish, 2015) because of their inadequate skill. For any teacher, experience (Yada et. al., 2018) and knowledge (Lu et. al., 2020) increases the self-efficacy which in turn contributes to the improvement of leadership quality among teachers and principals (Cohen, 2015). But Emam and Mohamed (2011) argued that experience increases positive attitude but has no effect on self-efficacy of teachers. It is also possible to make the in-service teachers more positively inclined towards inclusion if stakeholders come forward to assist them (Kantavong et. al. 2017).

Table 2: Predictors of self-efficacy

\begin{tabular}{llll}
\hline Authors & Year & Countries Studied & Predictors
\end{tabular}




\begin{tabular}{lcll}
\hline $\begin{array}{l}\text { Chao et. al. } \\
\text { Malinen et. al. }\end{array}$ & 2017 & $\begin{array}{l}\text { Hong Kong } \\
\text { China, Finland and South } \\
\text { Africa } \\
\text { China }\end{array}$ & $\begin{array}{l}\text { Teacher and school type } \\
\text { Experience in teaching CWD }\end{array}$ \\
Lu et. al. & 2020 & $\begin{array}{l}\text { Knowledge about inclusion and } \\
\text { positive attitude }\end{array}$ \\
Yada et. al. & 2018 & Japan and Finland & Experience in teaching CWD \\
\hline
\end{tabular}

Different variables predicted self-efficacy of in-service teachers in different countries. Teacher's confidence and school type were the predictors of self-efficacy among primary and secondary in-service teachers of Hong Kong (Chao et. al. 2017). But Yada et. al., (2018) pointed out that experience in teaching CWD was the strong predictor of self-efficacy in Japan and Finland which was also the conclusion given by Malinen et. al. (2013) after conducting a study in China, Finland and South Africa. On the other hand, Lu et. al. (2020) concluded that knowledge on inclusion and positive attitude predicted self-efficacy of teachers towards inclusive education in China.

\section{DISCUSSION AND FUTURE AGENDA:}

The analysis on the perception of in-service teachers towards inclusion of CWD was made based on geographical location. This categorization was made to understand the difference in the perception of teachers from two distinctly driven societies, i.e., a cultural or a development driven background. The perceptions taken up for the study included teacher's attitude, self-efficacy and confidence. Some notions were identified as common between the two groups. Though inclusive education was born in the West, negative perception was also seen among the teachers towards the inclusion of CWD. There was also a lack of knowledge about the requirements of special needs and national policies on inclusive education. The main reason for negative perception in the East was because the teachers lacked knowledge on IE, inadequate training, limited resources etc. The difference in the perception on socio-cultural ethos in Eastern countries influenced the intention to include CWD in regular schools but the work pressure and time constraints of Western teachers determined the perception towards the inclusion. Positive sentiments towards inclusion was seen among both the groups. The Western teachers were having positive sentiment but were not ready to include those children who showed negative work attitude.

Teachers of the East also had positive sentiments and were ready to include CWD but the only problem faced by them was the lack of support from stakeholders. Both teacher groups faced external difficulties that restricted their intention to include CWD in regular classroom. Governments implement policies and legislations in macro level. This is one of the drawbacks because the policies do not consider the ground level problems and personal difficulties faced by teachers while including CWD. Teachers play the critical role in teaching these children and thus are quite exposed to the direct implications of the IE policy. Instead of solely focusing on just including CWD in inclusive classrooms, policy makers and inclusive supporters should also take the difficulties faced by teachers into account. Teachers have to be equipped with all necessary skills and resources which would automatically make teachers more confident and willing to include CWD. The study can be further improved by including pre-service teachers and widening the analysis by including more databases in the study. This would help in understanding the process of training 
provided to pre-service teachers in different countries and the influence of training on inclusion.

\section{References}

Alevriadou, A., \& Pavlidou, K. (2014). Teachers Beliefs about the Factors Affecting the Positive Outcome of Intervention in Managing Challenging Behaviors of Individuals with Intellectual Disabilities. Procedia - Social and Behavioral Sciences, 159, 132-136.

Andriichuk, N. (2017). Historical background of inclusive education development in the Nordic countries. Journal of Vasyl Stefanyk Precarpathian National University, 4, 97-104, 10.15330/jpnu.4.1.

Chao, C. N. G., Sze, W., Chow, E., Forlin, C., \& Ho, F. C. (2017). Improving teachers self-efficacy in applying teaching and learning strategies and classroom management to students with special education needs in Hong Kong. Teaching and Teacher Education, 66, 360-369.

Cohen, E. (2015). Principal Leadership Styles and Teacher and Principal Attitudes, Concerns and Competencies regarding Inclusion. Procedia - Social and Behavioral Sciences, 186, 758-764.

Costea-BÄfrluÅiu, C., \& Rusu, A. S. (2015). A Preliminary Investigation of Romanian University Teachers Attitudes towards Disabilities " A Premise for Inclusive Interaction with Students with Disabilities. Procedia - Social and Behavioral Sciences, 209, 572-579.

Das, A., \& Kattumuri, R. (2010). Children with disabilities in private inclusive schools in Mumbai: Experiences and challenges. Asia Research Centre Working Papers, 34, 1-52.

Deng, M., \& Poon-McBrayer, K. F. (2004). Inclusive education in China: Conceptualisation and realisation. Asia Pacific Journal of Education, 24(2), 143-156.

Dev, S., \& Kumar, J. (2015). Teacher's Perception towards Integration of Learning Disabled Students into Regular Class Room "A Study in Dubai \& Abu Dhabi Schools. Procedia - Social and Behavioral Sciences, 211, 605-611.

Dias, P. C. (2015). For a Qualitative Leap in Inclusion: Illusions and Delusions from Teacher's Perspective. Procedia - Social and Behavioral Sciences, 191, 1119-1123.

Emam, M. M., \& Mohamed, A. H. H. (2011). Preschool and primary school teachers attitudes towards inclusive education in Egypt: The role of experience and self-efficacy. Procedia - Social and Behavioral Sciences, 29, 976-985.

Gavish, V. (2017). Four profiles of inclusive supportive teachers: Perceptions of their status and role in implementing inclusion of students with special needs in general classrooms. Teaching and Teacher Education, 61, 37-46.

Herwegen, J. V., Ashworth, M., \& Palikara, O. (2019). Views of professionals about the educational needs of children with neurodevelopmental disorders. Research in Developmental Disabilities, 91.

Hettiarachchi, S., \& Das, A. K. (2014). Perceptions of inclusion and perceived preparedness among school teachers in Sri Lanka. Teaching and Teacher Education, 43, 143-153.

Hosseinkhanzadeh, A. A., Yeganeh, T., \& Taher, M. (2013). Investigate Attitudes of Parents and Teachers About Educational Placement of Gifted Students. Procedia - Social and Behavioral Sciences, 84, 631-636.

Kalyanpur, M. (2008). Equality, quality and quantity: Challenges in inclusive education policy and service provision in India. International Journal of Inclusive Education, 12(3), 243-262.

Kim, Y. (2014). Inclusive education in South Korea. International Journal of Inclusive Education, 18(10), 979-990.

Kisanji, J. (1999, March). Historical and theoretical basis of inclusive education. In Keynote address for the Workshop on "Inclusive Education in Namibia: The Challenge for Teacher Education", 24-25.

Kantavong, P., Sujarwanto, Rerkjaree, S., \& Budiyanto, (2017). A comparative study of teacher's opinions relating to inclusive classrooms in Indonesia and Thailand. Kasetsart Journal of Social Sciences, 38(3), 291-296. 
Kormos, J., \& Nijakowska, J. (2017). Inclusive practices in teaching students with dyslexia: Second language teachers concerns, attitudes and self-efficacy beliefs on a massive open online learning course. Teaching and Teacher Education, 68, 30-41.

Lindsay, G. (2007). Educational Psychology and the effectiveness of inclusive education/mainstreaming. British Journal of Educational Psychology, 77(1), 1-24.

Lu, M., Zou, Y., Chen, X., Chen, J., He, W., \& Pang, F. (2020). Knowledge, attitude and professional selfefficacy of Chinese mainstream primary school teachers regarding children with autism spectrum disorder. Research in Autism Spectrum Disorders, 72, 101513.

MacFarlane, K., \& Woolfson, L. M. (2013). Teacher attitudes and behavior toward the inclusion of children with social, emotional and behavioral difficulties in mainstream schools: An application of the theory of planned behavior. Teaching and Teacher Education, 29, 46-52.

Malinen, O., Savolainen, H., \& Xu, J. (2012). Beijing in-service teachers' self-efficacy and attitudes towards inclusive education. Teaching and Teacher Education, 28(2), 526-534.

Malinen, O., Savolainen, H., Engelbrecht, P., Xu, J., Nel, M., Nel, N., \& Tlale, D. (2013). Exploring teacher self-efficacy for inclusive practices in three diverse countries. Teaching and Teacher Education, 33, 34-44.

Moher, D., Liberati, A., Tetzlaff, J., \& Altman, D. G. (2009). Preferred reporting items for systematic reviews and meta-analyses: The PRISMA statement. PLoS Med, 6(7), e1000097. DOI: 10.1371 / journal.pmed.1000097.

Parey, B. (2019). Understanding teachersâ $€^{\mathrm{TM}}$ attitudes towards the inclusion of children with disabilities in inclusive schools using mixed methods: The case of Trinidad. Teaching and Teacher Education, 83, 199-211.

Pather, S. (2019). Confronting inclusive education in Africa since Salamanca. International Journal of Inclusive Education, 23(7-8), 782-795.

Payraud, G. (2018). Challenges for inclusive education in Burkina Faso. Childhood Education, 94(6), 7478.

Pozo-Armentia, A. D., Reyero, D., \& Cantero, F. G. (2020). The pedagogical limitations of inclusive education. Educational Philosophy and Theory, DOI: 10.1080/00131857.2020.1723549.

Segall, M. J., \& Campbell, J. M. (2012). Factors relating to education professionalsâ $€^{\mathrm{TM}}$ classroom practices for the inclusion of students with autism spectrum disorders. Research in Autism Spectrum Disorders, 6(3), 1156-1167.

Sharma, U., \& Jacobs, D. K. (2016). Predicting in-service educators' intentions to teach in inclusive classrooms in India and Australia. Teaching and Teacher Education, 55, 13-23.

Singal, N. (2005). Mapping the field of inclusive education: A review of the Indian literature. International Journal of Inclusive Education, 9(4), 331-350.

Singal, N. (2011). Disability, poverty and education: Implications for policies and practices. International Journal of Inclusive Education, 15(10), 1047-1052.

Tiwari, A., Das, A. K., \& Sharma, M. (2015). Inclusive education a rhetoric or reality? Teachers' perspectives and beliefs. Teaching and Teacher Education, 52, 128-136

Todorovic, J., Stojiljkovic, S., Ristanic, S., \& Djigic, G. (2011). Attitudes towards Inclusive Education and Dimensions of Teacher's Personality. Procedia - Social and Behavioral Sciences, 29, 26-32.

Unianu, E. M. (2012). Teachers attitudes towards inclusive education. Procedia - Social and Behavioral Sciences, 33, 900-904.

Varcoe, L., \& Boyle, C. (2014). Pre-service primary teacher's attitudes towards inclusive education. International Journal of Experimental Educational Psychology, 34(3), 323-337.

BendovÃ, P., \& Fialov, A. (2015). Inclusive Education of Pupils with Special Educational Needs in Czech Republic Primary Schools. Procedia - Social and Behavioral Sciences, 171, 812-819.

Vermeulen, J. A., Denessen, E., \& Knoors, HH. (2012). Mainstream teachers about including deaf or hard of hearing students. Teaching and Teacher Education, 28(2), 174-181.

Vislie, L. (2003). From integration to inclusion: Focusing global trends and changes in the Western European societies. European Journal of Special Needs Education, 18(1), 17-35. 
Woodcock, S., Hitches, E., \& Jones, G. (2019). It's not you, it's me: Teachers self-efficacy and attributional beliefs towards students with specific learning difficulties. International Journal of Educational Research, 97, 1007-1118.

Woodcock, S., \& Woolfson, L. M. (2019). Are leaders leading the way with inclusion? Teachersâ€ $€^{\mathrm{TM}}$ perceptions of systemic support and barriers towards inclusion. International Journal of Educational Research, 93, 232-242.

Yada, A., \& Savolainen, H. (2017). Japanese in-service teachers attitudes toward inclusive education and self-efficacy for inclusive practices. Teaching and Teacher Education, 64, 222-229.

Yada, A., Tolvanen, A., \& Savolainen, H. (2018). Teachers' attitudes and self-efficacy on implementing inclusive education in Japan and Finland: A comparative study using multi-group structural equation modelling. Teaching and Teacher Education, 75, 343-355.

Young, K., McNamara, P. M., \& Coughlan, B. (2017). Authentic inclusion-utopian thinking? â€" Irish post-primary teachers' perspectives of inclusive education. Teaching and Teacher Education, 68, 111. 